Abstract P3-S1.34 Table 1 Sample Type Cx

\begin{tabular}{|c|c|c|c|c|c|c|}
\hline Sample type & $\mathbf{n}$ & CT sensitivity $[95 \% \mathrm{CI}]$ & CT specificity $[95 \%$ CI $]$ & $\mathbf{n}$ & NG sensitivity $[95 \% \mathrm{CI}]$ & NG specificity $[95 \%$ Cl] \\
\hline ES & 4253 & $\mathbf{9 1 . 6} \%(240 / 262)$ [87.6 to 94.4$]$ & $\mathbf{9 9 . 8 \%}(3984 / 3991)$ [99.6 to 99.9$]$ & 4252 & $\mathbf{9 5 . 6 \%}(65 / 68)[87.8$ to 98.5$]$ & $100 \%(4182 / 4184)$ [99.8 to 100$]$ \\
\hline LBC Prequot & 4238 & $\mathbf{9 2 . 8} \%(246 / 265)$ [89.1 to 95.4$]$ & $\mathbf{9 9 . 6 \%}(3958 / 3973)$ [99.4 to 99.8$]$ & 4239 & $\mathbf{9 7 . 1 \%}(67 / 69)[90.0$ to 99.2$]$ & $\mathbf{9 9 . 9 \%}(4167 / 4170)$ [99.8 to 100$]$ \\
\hline LBC Postquot & 4202 & $89.7 \%(235 / 262)$ [85.4 to 92.8$]$ & $\mathbf{9 9 . 7 \%}(3930 / 3940)$ [99.5 to 99.9$]$ & 4203 & $\mathbf{9 5 . 7 \%}(66 / 69)[88.0$ to 98.5$]$ & $100 \%(4132 / 4134)$ [99.8 to 100.0$]$ \\
\hline
\end{tabular}

locations. Endocervical swabs (ES) and samples in ThinPrep liquid based cytology medium (LBC) were obtained from each participant as were urine samples (data not shown) and vaginal swabs (data not shown). LBC were sampled prior to cytology (prequot) for cobas and AC2 and after cytology (postquot) for cobas only. A patient was considered infected if at least 2 of the assays with different molecular targets gave positive results from the ES or urine samples.

Results Overall CT sensitivity ranged from 89.7 to $92.8 \%$ and specificity ranged from 99.6 to $99.8 \%$ for all sample types. Overall GC sensitivity ranged from 95.6 to $97.1 \%$ and specificity from 99.9 to $100 \%$ see Abstract P3-S1.34 table 1.

Conclusions The cobas assay has excellent sensitivity and specificity when compared to PIS. Equivalent performance was observed for the ES and LBC samples, providing clinicians with flexibility to tailor endocervical sample acquisition to their particular setting. There was no statistical difference between the pre- and post-quot LBC samples allowing specimen handling to be suited to the needs of the microbiology and cytology laboratories. The assay is easy to perform, automated, and can be completed in $<4 \mathrm{~h}$.

\section{P3-S1.35 SYSTEMIC AND MUCOSAL IGG AND IGA ANTIBODY RESPONSES IN GENITAL CHLAMYDIA TRACHOMATIS INFECTION}

doi:10.1136/sextrans-2011-050108.435

${ }^{1} \mathrm{R}$ Wiggins, ${ }^{2} \mathrm{G}$ Morris, ${ }^{3} \mathrm{~L}$ Habgood, ${ }^{2} \mathrm{C}$ Lacey. ${ }^{1}$ University of York, York, UK; ${ }^{2}$ Hull York Medical School, UK; ${ }^{3}$ Monkgate Health Centre, UK

Background Chlamydia trachomatis (CT) is the most common sexually transmitted infection in the UK. Screening and treatment programmes do not appear to have reduced the population levels of Chlamydia. Ideally a vaccine stimulating both humoural and $\mathrm{T}$-cell responses against CT should be developed. We therefore wished to further study the humoural immune response to chlamydial infection both systemically and mucosally in the female genital tract in natural infection.

Methods Cervical secretions (obtained with Weck-Cel spears, Medtronic) and serum from twenty-six women diagnosed chlamydia-positive were assessed for Chlamydia-specific IgA and IgG responses (Anilab systems, Finland) at baseline and at 4 months follow-up. Samples from thirty chlamydia-negative women were used as controls. The Mann-Whitney non-parametric test was used to compare groups.

Results There was a significant difference between CT+ve and CT-ve IgG in serum samples (IgG median absorbance values $\mathrm{p}=0.006$, median CT-ve samples 0 , +ve samples 0.255 ) and IgA serum values ( $p=0.005$, CT +ve median 0.491 , CT-ve 0.119 ). There was no significant difference between cervical IgG and IgA levels between CT+ve and CT-ve women (IgG median absorbance values, CT+ve samples 0.012, 0 CT-ve; IgA CT-ve 0.202, CT+ve, $0.032)$, although there was a trend towards raised cervical IgG in CT +ve samples $(p=0.08)$. There was no significant difference between antibody levels at baseline and 4 months for the $10 \mathrm{CT}+$ ve women who have returned so far.

Discussion Our data suggests that the local and systemic antibody responses to genital chlamydial infection are highly variable. No CT +ve samples studied display positive absorbance levels in all four tested parameters. However, serum IgG and IgA responses are significantly raised in CT+ve individuals, and these values remain high at 4 months follow-up. This is in contrast to local responses which are not significantly different between CT+ve and CT-ve individuals, although there is a trend towards raised cervical IgG in $\mathrm{CT}+\mathrm{ve}$ samples. The results of this study so far indicate that local immune responses, in comparison to systemic responses, are not well-defined. This may have implications both for chlamydial vaccine development, and mucosal assessment of candidate vaccines.

\section{P3-S1.36 ASSESSING THE DIAGNOSIS AND TREATMENT OF URETHRITIS AMONG MEN ATTENDING AN URBAN STD CLINIC}

doi:10.1136/sextrans-2011-050108.436

${ }^{1} \mathrm{~B}$ W Furness, ${ }^{2} \mathrm{E}$ A Sheriff, ${ }^{3} \mathrm{~S}$ Sankar, ${ }^{3} \mathrm{~N}$ Kamanu Elias. ${ }^{1} \mathrm{CDC} / \mathrm{NCHHSTP/DSTDP/ESB/}$ FEU, Washington, USA; ${ }^{2}$ George Washington University, Washington, USA; ${ }^{3}$ Department of Health, District of Columbia, Washington, USA

Background Urethritis is inflammation of the urethra, the main symptoms of which are dysuria and discharge, and two of the most common causes of which are Chlamydia trachomatis and Neisseria gonorrhoeae. The objectives of this study were to: (1) Determine the prevalence of atypical urethritis among participants, (2) Assess the sensitivity and specificity of using gram stain to diagnose gonorrhoea, and (3) Evaluate the effect of diagnostic test used on the time to treatment.

Methods A random sample of 600 eighteen to 60-year-old men who visited the SE STD Clinic from January 2008 to December 2009 and had a gram stain and nucleic acid amplification test (NAAT) performed were studied. Atypical urethritis was defined as having evidence of inflammation on gram stain but no evidence of gonorrhoea (ie, NGU) and a NAAT negative for both bacteria. The sensitivity and specificity of gram stain were calculated using NAAT as the gold standard. An analysis of variance was used to assess the relationship between time to treatment and diagnostic test-F statistics and corresponding $p$ values were calculated. All statistical analyses were performed using SAS software V. 9 (SAS Institute Inc.) and WinPepi (Abramson, J.H. Epidemiologic Perspective and Innovations).

Results Of the 600 cases, 493 (82.3\%) were Black, 253 (42.2\%) had clinical urethritis, and $204(47.0 \%)$ had a previous STD history. The mean age was 30.6 years $(\mathrm{SD}=10.3)$. One hundred and five cases of gonorrhoea, 110 cases of chlamydia, and three co-infections were diagnosed (Abstract P3-S1.36 table 1). None of the men diagnosed with gonorrhoea via gram stain were co-infected with chlamydia. The prevalence of atypical urethritis among this study population was $31.2 \%$. The sensitivity of gram stain was $84.3 \%$, the specificity was $100 \%$, the positive predictive value (PPV) was $100 \%$, and the negative predictive value (NPV) was $96.7 \%$. The mean time to treatment was 2.52 days $(S D=2.17)$. Analysis of variance revealed that gram stain $(F=41.50, p<0.0001)$ and NAAT $(\mathrm{F}=19.18, \mathrm{p}<0.0001)$ had significantly different effects on time to treatment. 